\title{
Rheumatic manifestations in autoimmune liver disease
}

Carlo Selmi $^{1,2}$, Elena Generali ${ }^{1}$, M. Eric Gershwin ${ }^{3}$

${ }^{1}$ Division of Rheumatology and Clinical Immunology, Humanitas Research Hospital, Rozzano, Milan, Italy; ${ }^{2}$ BIOMETRA Department, University of Milan, Milan, Italy; ${ }^{3}$ Division of Rheumatology, Allergy, and Clinical Immunology, University of California, Davis

Corresponding author: Carlo Selmi MD PhD, Division of Rheumatology and Clinical Immunology, Humanitas Research Hospital, via A. Manzoni 56, 20089 Rozzano, Milan, Italy; tel +39-02-8224-5129, fax +39-02-8224-2298, email carlo.selmi@unimi.it

Disclosure statement: the Authors have no conflicts of interest.

Key words: immune tolerance; personalized medicine; autoimmune comorbidity; cholangitis; hepatitis; osteoporosis; methotrexate; biomarker; autoantibody

\section{Key points:}

- AIH is a rare disease, which is the result of an autoimmune destruction of the hepatocytes, manifesting with high liver aminotranferases and serum autoantibodies that may be specific for the disease.

- PBC and PSC are chronic autoimmune cholestatic diseases that affect the biliary tree. PBC is characterized by AMA positivity in almost all cases, while conversely, PSC has no association with autoantibodies, suggesting a different pathogenesis.

- Rheumatic diseases are found in nearly $20 \%$ of patients suffering from autoimmune liver diseases, and may be associated with different prognoses for the patients. For this reason, the identification of 
the co-occurrent disease at an early stage or even pre-clinically (using autoantibodies) is of pivotal importance.

- Bone density is reduced in patients with AIH due to prolonged steroid use and in PBC / PSC due to chronic cholestasis; therefore, osteoporosis management is an important issue in the care of these patients.

- Treatment options should be personalized to address coexisting conditions, especially if overlapping with specific rheumatic or autoimmune diseases. 
Abstract.

Autoimmune liver diseases coexist with rheumatic disorders in approximately $30 \%$ of cases and may also share pathogenetic mechanisms. Autoimmune liver diseases result from an immunemediated injury of different tissues, with autoimmune hepatitis (AIH) targeting hepatocytes, primary biliary cholangitis (PBC) and primary sclerosing cholangitis (PSC) targeting cholangiocytes. Sjögren's syndrome is diagnosed in 7\% of AIH cases and serological autoimmunity profiles are a common laboratory abnormality, particularly in the case of serum anti-mitochondrial (PBC) or anti-liver kidney microsomal antibodies (AIH). Therapeutic strategies may overlap between rheumatic and autoimmune liver diseases and practitioners should be vigilant in managing bone loss. 


\section{Introduction.}

The link between autoimmune liver diseases and rheumatologic disease traces back to the first report in the mid-1950s, when findings of active chronic hepatic disease were described in the setting of systemic lupus erythematosous (SLE). This led to the concept of "lupoid hepatitis" with positive LE cell tests and mild signs of rheumatic disease ${ }^{1,2}$. When discussing autoimmune liver disease, it is possible to distinguish autoimmune hepatitis (AIH, affecting hepatocytes) from primary biliary cholangitis (PBC, until recently known as primary biliary cirrhosis), and primary sclerosing cholangitis (PSC) based on the target tissue ${ }^{3,4}$. Cirrhosis and liver failure are potential complication shared by inflammatory hepatobiliary diseases, regardless of the target tissue, while the pathogenesis and therapeutics may vary within the clinical spectrum ${ }^{5}$. The epidemiology of autoimmune liver diseases is similar to other rare autoimmune or inflammatory disorders. ${ }^{6-8}$ Similarly, serum autoantibodies represent the hallmark for AIH and PBC, but not PSC, and are usually positive years before the diagnosis (Table 1) ${ }^{9-11}$.

Since the earliest reports, several others have shown the associations between PBC and systemic sclerosis (SSc), ${ }^{12,13}$ as well as Sjögren's syndrome $(\mathrm{SjS}){ }^{14}$. Moreover, the epidemiologic links between these liver diseases and systemic rheumatic manifestations, are also reflected in shared pathogenetic mechanisms. This is elegantly represented by the concept of "autoimmune epithelitis," coined as a descriptor for PBC and SjS ${ }^{15}$. Serological profiles are also similar with regard to antinuclear antibodies (ANA) positivity ${ }^{16}$ and common laboratory abnormalities are present, as is the case for hypergammaglobulinemia ${ }^{17}$. Most importantly, therapeutic strategies may also overlap, since steroids represent the first-line therapy in most cases ${ }^{18}$, while new targeted approaches are emerging ${ }^{19,20}$. Non-classical associations have been also reported between spondyloarthritis and PSC, with regard to inflammatory bowel diseases (IBD) ${ }^{21}$. Finally, since corticosteroids and chronic liver diseases are associated with bone density loss, osteoporosis and bone fractures are conditions demanding the attention of the rheumatologist managing such patients $22-24$. 
The aims of the present review are 1) to provide an overview of the characteristics of the three major autoimmune liver diseases, namely AIH, PBS and PSC; 2) elucidate the existing associations between these conditions and rheumatic diseases. Particular attention is paid to both the shared and unique epidemiology, serum autoantibodies, and treatments, as well as the approach to bone density loss.

\section{Autoimmune hepatitis.}

$\mathrm{AIH}$ is a chronic inflammatory disease of unknown etiology resulting from the immune-mediated destruction of hepatocytes with autoimmune features ${ }^{25,26}$. AIH is characterized by the presence of typical but non-specific findings on liver biopsy, serum autoantibodies, and elevated serum aminotransferases and gamma-globulins ${ }^{27}$. The incidence, though not precise, , is estimated at approximately 1 per 100,000 person-years, with higher possible incidence in Scandinavia ${ }^{28}$. AIH most commonly affects women, with a male:female ratio of $1: 4^{28}$, and manifests a two-peak incidence during adolescence and at 30-45 years of age ${ }^{25,29}$. The onset of AIH is most frequently insidious, with $20-30 \%$ of patients presenting with an acute icteric hepatitis, consistently associated with hypergammablubulinemia. Clinical manifestations are non-specific and include hepatosplenomegaly, jaundice, anorexia and fatigue ${ }^{27,30}$. The most common extrahepatic manifestations are arthralgia and rash.

\section{Clinical features}

Two types of AIH are distinguished, primarily based on autoantibody patterns; i.e. AIH type 1 with ANA and/or anti-smooth muscle antibodies (anti-SMA), and AIH type 2 with anti-liver kidney microsomal type 1 antibody (anti-LKM1) and/or anti-liver cytosol type 1 antibody (anti-LC1). Type I AIH (AIH-1) can affect individuals of any age and sex. Patients with HLA DRB1*0301 AIH-1 are more likely to be male, present with high IgG levels, be ANA/anti-SMA positive, deteriorate despite glucocorticoid treatment, and progress more frequently to liver transplantation. Type II AIH (AIH-2), primarily affects girls and young women, and has been linked to alleles encoding the DR3 
$\left(\mathrm{DRB} 1{ }^{*} 0301\right)$ and DR7 (DRB1*0701) molecules ${ }^{26}$. It also associates with anti-LKM antibodies 27,31,32. The diagnosis of AIH is defined as definite or probable, based on the Diagnostic Criteria of the International Autoimmune Hepatitis Group (IAIH-G, Table 2) ${ }^{33,34}$. The clinical criteria for the diagnosis are sufficient to establish or rule out a definite or probable AIH in the majority of patients. The revised scoring system was developed as a research tool to ensure the comparability of study populations in clinical trials, and can be used to assess treatment response (Table 3), similar to classification criteria utilized in rheumatology ${ }^{34}$. A pretreatment score of 10 points or higher, or a posttreatment score of 12 points or higher, indicate "probable" AIH at presentation, with a sensitivity of $100 \%$, a specificity of $73 \%$, and diagnostic accuracy of $67 \%$. A pretreatment score of 15 points, indicative of "definite AIH” has a sensitivity of $95 \%$, a specificity of $97 \%$, and a diagnostic accuracy of $94 \%{ }^{35}$.

The clinical course of untreated AIH results in significant mortality, with 5- and 10-year survival rates of $50 \%$ and $10 \%$ respectively. The use of glucocorticoids has dramatically improved the disease course with a 10 -year survival rate now exceeding $90 \%{ }^{25}$. The complications associated with $\mathrm{AIH}$ are similar to those of other progressive liver diseases, as chronic hepatitis can evolve to cirrhosis and ultimately to hepatocellular carcinoma (HCC), despite the use of immunosuppressives. At the time of diagnosis, approximately $30 \%$ of adults have histological evidence of cirrhosis; when appropriately treated, however, only a small number develop cirrhosis during follow-up if biochemical and histology inflammation resolves. The occurrence of HCC in patients with AIH is rare and only develops in long-standing cirrhosis. In the absence of definitive data, primary liver neoplasia incidence is assumed to be similar to other non-viral cases of cirrhosis ${ }^{25}$.

\section{Association with rheumatic diseases}

AIH was originally described in association with SLE and currently extrahepatic autoimmune manifestations are found in $20-50 \%$ of patients ${ }^{36}$, with the most common being autoimmune thyroiditis, diabetes, rheumatoid arthritis (RA) and ulcerative colitis (UC). Up to $43 \%$ of AIH cases will have a family history of autoimmune diseases, in particular thyroid diseases and type 1 diabetes 
37. The occurrence of other autoimmune diseases in AIH is included in the original and revised International Autoimmune Hepatitis Scoring System (Table 3) ${ }^{33}$. Concurrent autoimmune disorders tend to cluster in women with AIH type 1, particularly if positive for the human leukocyte antigen (HLA)-DR4 ${ }^{38}$. Moreover, elderly patients with AIH have higher frequency of concurrent rheumatic conditions than young adults ${ }^{39}$. SjS has been reported in up to $7 \%$ of $\mathrm{AIH}$ patients, while RA in $2-4 \%$. Though liver dysfunction has been reported in up to $60 \%$ of SLE patients, the overlapping with $\mathrm{AIH}$ is rare ${ }^{36}$.

An AIH-like entity linked to anti-TNF treatment has recently been described in case reports. ${ }^{40}$ Though these result in a significant liver injury, the pathogenesis remains clear ${ }^{41}$. Liver biopsy appears useful, however the differentiation between drug-induced liver injury is not an easy task. Interestingly, most cases respond well to corticosteroids ${ }^{42}$.

\section{Autoantibodies}

Autoantibodies represent a critical feature of AIH and may guide the diagnosis (Table 2). In 2004, the IAIH-G established procedures and reference guidelines for more reliable serum autoantibody testing to overcome the lack of standardization ${ }^{43}$. In addition to serum ANA, anti-SM, and antiLKM, ${ }^{44}$ other autoantibodies should also be sought in suspected cases, including anti-LC1, perinuclear anti-neutrophil cytoplasmic antibodies (pANCA), SLA/LP, and the anti asialoglycoprotein receptor antibodies ${ }^{45}$. Finally, less specific autoantibodies may be detected in a subset of patients, including anticardiolipin, anti-chromatin, anti-dsDNA, rheumatoid factor (RF), anti-histones, anti-Ro/SSA, and anti-cyclic citrullinated peptides (anti-CCP) antibodies. Serum ANA were the first autoantibodies observed in AIH sera over 50 years ago and remain the most sensitive marker of AIH ${ }^{46}$. These most frequently produce a homogeneous or speckled pattern. However, the test is not specific for AIH, since ANA positivity is not uncommon in viral diseases, other autoimmune liver diseases, as well as in up to $15 \%$ of healthy subjects, especially in older age groups ${ }^{47}$. Serum SMA are autoantibodies reacting with different proteins (actin, tubulin, vimentin, desmin, cytokeratins) of the cytoskeletal components (microfilaments, microtubuli, intermediate 
filaments). Their presence characterizes both autoimmune (AIH-1, coeliac disease) and viral diseases (chronic hepatitis $\mathrm{C}$, infectious mononucleosis). When detected at high titers $(>1: 80)$, they are considered a sensitive marker for AIH-1, being found in up to $80 \%$ of cases. A recent study showed that anti- SMA-T/G positive subject with normal liver function are at low risk of progression to AIH, while positive SMA and raised ALT ( $>55 \mathrm{IU} / \mathrm{L})$ are at higher risk, though the positive predictive value is only $22 \%{ }^{48}$. Serum autoantibodies against LKM-1 are the main serological markers of AIH-2, recognizing the proximal renal tubule and hepatocellular cytoplasm. Serum anti-SLA/LP antibodies are occasionally found in AIH patients who are negative for ANA, SMA, or anti-LKM and are cumulatively detected in $10-30 \%$ of cases of AIH-1 and -2. AntiSLA/LP antibodies are detectable by radioimmunoassay and enzyme-linked immunosorbent assay (ELISA) but not by immunofluorescence and are directed against different epitopes of a UGA tRNA suppressor. Anti-LC1 antibodies are detected by indirect immunofluorescence in sera from up to $50 \%$ of patients with type $2 \mathrm{AIH}$ and less frequently in type $1 \mathrm{AIH}$ or chronic hepatitis $\mathrm{C}$. Importantly, however, anti-LC1 are the only detectable markers in $10 \%$ of $\mathrm{AIH}$ cases. Interestingly, serum anti-LC1 antibodies correlate with $\mathrm{AIH}$ severity and progression. Antibodies to the asialoglycoprotein receptor are observed in up to $90 \%$ of patients with AIH and often coexist with other autoantibodies, though they lack specificity for the disease. Similar to anti-LC1, however, anti-asialoglycoprotein titers are associated with a more florid inflammatory disease activity and may allow monitoring of treatment response.

With regard to non-specific antibodies, anti-CCP can be found in $9 \%$ of AIH sera, and their detection is independent of concurrent RA but may distinguish early stage RA from nonspecific arthralgia ${ }^{39}$. Moreover, it has been reported than anti-CCP positive subjects are at higher risk of cirrhosis at diagnosis and die more frequently from hepatic failure ${ }^{21}$. Anti-cardiolipin antibodies occur in nearly $40 \%$ of $\mathrm{AIH}$, which is more frequently than hepatitis C (20\%) and B (14\%) infections. The presence of anti-cardiolipin $\mathrm{IgG} / \operatorname{IgM}$ is associated with cirrhosis and inflammatory activity ${ }^{49}$, with the IgM subtype being more frequent in AIH than PBC ${ }^{50}$. Further, pANCA can be 
detected by indirect immunofluorescence in sera from patients with AIH-1, but also in a subgroup of patients with PSC or chronic viral hepatitis. Antibodies to histones are present in 35\% of ANApositive patients with autoimmune hepatitis, while anti-dsDNA are detected in $23-34 \%$ cases, depending on the nature of the assay and substrate used for their detection ${ }^{51}$. Patients with antihistones are not distinguished by the severity of their disease ${ }^{52}$, while anti-dsDNA positive subjects do not respond or respond less to corticosteroid treatment ${ }^{53}$.

\section{Therapy}

In contrast to PBC and PSC, immunosuppressants represent the treatment of choice for AIH, based on the good bio-chemical and histologic response, and survival (Table 4) ${ }^{43,54}$. Glucocorticoids--in particular prednisone--in monotherapy or in combination with azathioprine are the first-line treatment. These induce remission (i.e. normal ALT and $\mathrm{IgG}$ ) in over $80 \%$ of the patients, regardless of the presence of cirrhosis ${ }^{31}$. Once achieved, remission can be maintained with azathioprine alone after steroid tapering. The dosage of azathioprine is typically low compared to rheumatic diseases, usually requiring only $50 \mathrm{mg}$ /day and never exceeding $150 \mathrm{mg} /$ day ${ }^{18}$. Relapses following steroid discontinuation are common, since only $20 \%$ of patients remain in sustained remission. It should be noted, however, that subgroups of patients manifest disease progression (approximately 10\%) or are intolerant to standard therapy (13\%). In such patients, other drugs have been anecdotally tried, including methotrexate ${ }^{55}$, cyclophosphamide, tacrolimus, ursodeoxycholic acid, cyclosporine and mycophenolate mofetil, the latter two constituting the most frequently reported alternatives ${ }^{18,56}$. Biologic therapies commonly used in rheumatology are of particular interest, as pro-inflammatory cytokines, i.e. tumor necrosis factor (TNF)-alpha, are involved in AIH pathogenesis ${ }^{18}$. Infliximab has been used in refractory cases of AIH with reduction of aminotransferases and IgG levels ${ }^{57}$. Rituximab has been tried in a few refractory AIH cases, resulting in improved liver enzymes and IgG, no significant side effects, and a reduction in prednisolone dose for some patients ${ }^{58}$. Future developments may include regulatory $\mathrm{T}$ cell therapy, which could allow the avoidance of prolonged often life-long global immunosuppression in patients 
with $\mathrm{AIH}{ }^{59}$. Liver transplantation is the most definitive treatment for AIH patients presenting with acute liver failure or end-stage chronic liver disease and for those with HCC that meet the transplant criteria. Although liver transplantation for these patients is very successful, AIH may recur after transplant. AIH patients undergoing liver transplant have overall 5- and 10-year survival rates of $90 \%$ and $75 \%$, respectively, although infectious complications and disease recurrence are common 60-63.

\section{Primary biliary cholangitis}

$\mathrm{PBC}$ is a chronic cholestatic disease characterized by high-titer serum anti-mitochondrial antibodies (AMA) in nearly $100 \%$ of patients when sensitive techniques are used ${ }^{64}$ It results in autoimmunemediated destruction of the small and medium-sized intrahepatic bile ducts ${ }^{17,65}$. PBC prevalence varies substantially according to geography; the highest rates appear in the northern US with a point prevalence of 402 per million in Minnesota ${ }^{66}$. Similar to other autoimmune diseases, PBC most commonly affects women, with a 1:9 male:female ratio ${ }^{17}$, and the average age at PBC diagnosis is within the 5 th and 6 th decades of life ${ }^{17}$.

Recently, PBC nomenclature has shifted from the term "cirrhosis" to "cholangitis", which is more precise and removes the stigma associated with cirrhosis. This change reflects the dramatically improved PBC prognosis and treatment, since nowadays, two out of three patients diagnosed with PBC and treated with ursodeoxycholic acid (UDCA) have an expected survival comparable to the general population and only a minority will ever develop cirrhosis 67,68 .

\section{Clinical features}

Early PBC symptoms are classically described as fatigue and pruritus while physical findings may include skin hyperpigmentation, hepatosplenomegaly, and (rarely) xanthelasmas. Fatigue and pruritus are nonspecific symptoms present in $70 \%$ of $\mathrm{PBC}$ patients. Conversely, end-stage symptoms are secondary to the complications of liver cirrhosis, including ascites, jaundice, hepatic encephalopathy, and upper digestive bleeding. Portal hypertension is frequently found in patients 
with PBC and, importantly, does not imply the presence of liver cirrhosis. Metabolic bone disease is elevated in PBC compared to sex- and age-matched healthy individuals (see below). Similar to other types of cirrhosis, end-stage PBC can be complicated by the occurrence of HCC. The progression of $\mathrm{PBC}$ varies widely, and the factors influencing the severity and progression of the disease are largely unknown. The presence of symptoms at presentation, however, are a major factor determining PBC survival rates; asymptomatic PBC produces 10-year survival rates shorter than the general population, but symptomatic PBC produces even shorter survival rates ${ }^{68}$. The diagnosis of PBC is generally based on the presence of two of the following three criteria: (1) biochemical evidence of cholestasis with elevation of alkaline phosphatase activity over six months; (2) presence of serum AMA at significant titers; and (3) histological non-suppurative cholangitis and destruction of small or medium-sized bile ducts on biopsy specimen. The differential diagnosis includes a cholestatic drug reaction, biliary obstruction, sarcoidosis, AIH and PSC (Table 4) ${ }^{69}$.

\section{Association with rheumatic diseases}

$\mathrm{PBC}$ is commonly associated with a number of extrahepatic autoimmune conditions. A recent monocentric study identified a co-occurrence in more than $60 \%$ of patients, with the most common being $\mathrm{SjS}$ in $30 \%$ of patients, followed by Raynaud's phenomenon in $18 \%$, and Hashimoto's thyroiditis. PBC and SSc are associated in $6 \%$ of cases ${ }^{70}$, while a higher frequency of RA (up to $10 \%$ ) has been reported since the $1970 \mathrm{~s}^{71},{ }^{72}$. PBC has also been reported in the presence of HLAB27 enthesopathy. ${ }^{73}$ Interestingly, $5 \%$ of PBC cases also suffer from autoimmune cutaneous conditions ${ }^{74},{ }^{75}$. Surprisingly, when extrahepatic autoimmune diseases co-occur with PBC, the cases tend to be less severe; severe $\mathrm{SjS}$ occurs in $10.5 \%$ of $\mathrm{PBC}$ cases, and the PBC disease is usually milder and at early stage (stage I-II at liver histology) in the presence of $\mathrm{SjS}{ }^{76,77}$. The same observation has been made with PBC and SSc. PBC most commonly associates with limited cutaneous SSc (1SSc), and patients with PBC/SSc overlap have a slower rate of liver-disease progression compared to matched patients with $\mathrm{PBC}$ alone ${ }^{78}$. Female sex is the only significant risk 
factor for at having a second autoimmune condition ${ }^{70}$, while neither autoantibodies nor liver histology differ.

\section{Autoantibodies}

PBC is characterized serologically by the presence of AMA, which are highly specific for the disease. These antibodies are found in $90-95 \%$ of PBC patients compared with less than $1 \%$ of healthy subjects ${ }^{79}$. Similar to other autoimmune diseases, AMA positivity arises years before the development of $\mathrm{PBC}^{9}$, and $\mathrm{AMA}$ are included in the internationally-accepted criteria for $\mathrm{PBC}$ diagnosis (Table 5) ${ }^{80}$. AMA are directed against components of the 2-oxoacid dehydrogenase (2OADC) family of enzymes within the mitochondrial respiratory chain, most frequently the E2 and E3-binding protein (E3BP) components of the pyruvate dehydrogenase complex and the E2 components of the 2-oxo glutarate dehydrogenase and branched-chain 2-oxo acid dehydrogenase complexes ${ }^{81}$. All three antigen epitopes contain the motif DKA, with lipoic acid covalently bound to the lysine $(\mathrm{K})$ residue ${ }^{78}$. ANA have been identified in $52 \%$ of patients, with the most specific patterns being "nuclear-rim" and "multiple nuclear dots", produced by antibodies directed against the nuclear membrane gp120 and nucleoporin 62, and the nuclear body sp100, sp140 and promyeolocytic leukaemia proteins, respectively (Table 1) ${ }^{82-85}$. ANA-positive patients are more frequently AMA-negative, possibly because of the lack of a masking effect of these latter antibodies in such sera. While ACA are most specific for 1SSc, found in up to $90 \%$ of cases, they are also detectable in $9-30 \%$ of $\mathrm{PBC}$ patients. This prevalence exceeds that of the $\mathrm{PBC} / \mathrm{SSc}$ overlap syndrome ${ }^{86,87}$. ACA recognize six centromere polypeptides belonging to the kinetochore proteins: CENP-A, CENP-B, CENP-C, CENP-D, CENP-E, CENP-F, with the major autoantigen being CENP-B. The clinical significance of ACA in PBC remains ill-defined as it is unclear whether ACA represents a pre-clinical marker of $1 \mathrm{SSc}$ or a subclinical form of the disease. Moreover, ACA could simply represent an epiphenomenon of the immune dysregulation present in $\mathrm{PBC}{ }^{78}$. Some have posited that since ACA can predict the development of SSc and since early SSc may be frequent in $\mathrm{PBC}$, these may facilitate timely detection of complications, preventing disability and 
reducing the probability of liver transplantation ${ }^{88},{ }^{78}$. In any case, patients with $\mathrm{PBC}$ and positive ACA with SSc-related symptoms should be assessed for organ involvement, and in particular, assessment of pulmonary arterial hypertension by echocardiography should be considered in all $\mathrm{PBC} / \mathrm{SSc}$ patients. Unfortunately, currently utilized tools to predict this pulmonary arterial hypertension (e.g. the DETECT score) have not been evaluated in PBC patients ${ }^{89}$. Furthermore, while $\mathrm{PBC} / \mathrm{SSc}$ seems to have a milder disease course, ACA positive $\mathrm{PBC}$ patients have a more severe bile duct injury and more frequently portal hypertension ${ }^{78}$. With regard to other autoantibodies ${ }^{90}$, anti-ENA are positive in up to $40 \%$ of PBC cases, regardless of the extrahepatic autoimmunity ${ }^{70}$, with no effect on disease severity or progression. Anti-Ro/SSA are found in $\mathrm{PBC} / \mathrm{SjS}$ overlap in $10 \%$ of cases ${ }^{90}$, anti-dsDNA in $22 \%$ of PBC patients ${ }^{90}$ while anti-cardiolipin IgM positive in $75 \%$ of $\mathrm{PBC}$, advanced stage disease ${ }^{91}$.

\section{Therapy}

PBC treatment is currently based on UDCA, which is the only approved drug. Its mechanism of action is incompletely understood and possibly dependent on the various phases of the disease ${ }^{5,92}$. During the early disease, short-term glucocorticoids might be effective, however, prolonged use raises safety concerns. Budesonide, due to its high first-pass metabolism, has minimum systemic adverse effects, and, at 6-9 mg daily, has been demonstrated to be superior to UDCA both in terms of histology and biochemical markers. Other immunosuppressants, such as methotrexate and azathioprine, have also been suggested and there is evidence supporting the use of the latter in PBC with autoimmune hepatitis overlap syndrome ${ }^{93}$. The use of biologics targeting TNF-alpha has been reported in few cases of overlap syndromes with rheumatic diseases ${ }^{94,95}$. In the last years, improved understanding of $\mathrm{PBC}$ pathogenesis has led to the testing of new targeted therapies, especially those modulating the IL-17/23 axis. Ustekinumab, a monoclonal antibody against the p40 subunit, however, demonstrated only a very modest decrease in ALP after 28 weeks of therapy, and was otherwise deemed ineffective ${ }^{19}$. Other therapies targeting $\mathrm{T}$ cells ${ }^{96}$, including those that bind CTLA-4 (abatacept) or antagonize CD40 (FFP104) are under investigation ${ }^{69,97,98}$. Of note, the use 
CTLA-4 Ig in PBC murine model prevents cholangitis manifestations (AMA production, intrahepatic T-cell infiltrates, and bile duct damage) and reduces disease severity in established murine disease ${ }^{99}$. When the disease has already progressed and bile is accumulated, obeticholic acid (OCA)--an analogue of chenodeoxycholic acid with a much higher affinity to the farnesoid X receptor (FXR)--has been shown to decrease bile synthesis, promote secretion, and induce liver regeneration in animal models. Furthermore, a recent Phase III trial of OCA administered with UDCA or as monotherapy for 12 months demonstrated decreases in alkaline phosphatase and total bilirubin levels compared with placebo ${ }^{97}$. Ultimately, UDCA represents the cornerstone therapy of $\mathrm{PBC}$ and dosages ranging from 13 to $15 \mathrm{mg} / \mathrm{kg}$ lead to optimum bile enrichment, with $50 \%$ of patients normalizing their alkaline phosphatase. Other immunosuppressive treatments should be started only in combination with UDCA.

Liver transplantation may be necessary for end-stage PBC, with survival rates of $92 \%$ and $85 \%$ at 1 and 5 years after transplant, respectively. Recurrence is common seems to be influenced by immunosuppressives, while the use of UDCA for recurrence is safe and recommended.

\section{Primary sclerosing cholangitis}

PSC is a progressive cholestatic liver disease of unknown etiology presenting with chronic inflammatory features of the bile ducts of any size and associated with significant morbidity and mortality ${ }^{100,101}$. In contrast to PBC, PSC can affect all tracts of the biliary tree, including the extrahepatic bile ducts visible with imaging modalities and the small bile ducts observed via liver histology. The prevalence of PSC is approximately 10/100000 in Northern Europe ${ }^{28}$ and in the US, while it is far less common in Southern Europe and Asia; recent data from the Olmstead County, Minnesota, report a prevalence of 20.9 per 100000 men and 6.3 per 100000 women ${ }^{102}$. Different from PBC and AIH, PSC affects more frequently men, with a 2:1 male:female ratio ${ }^{102}$.

Clinical features 
PSC symptoms are generally nonspecific and include abdominal pain, jaundice, and fever in the case of bacterial cholangitis, while at more advanced stages, symptoms include those typical of decompensated cirrhosis or neoplasia. Commonly, PSC is complicated by episodic bacterial cholangitis precipitated by biliary strictures. Discrete subgroups of patients manifest the "smallduct" or overlap syndrome variants. Due to the nonspecific symptoms, PSC is usually diagnosed during routine blood tests in otherwise healthy individuals or patients with IBD ${ }^{103}$. Testing characteristically reveals a biochemical cholestatic pattern, as represented by elevated serum alkaline phosphatase and $\gamma$-glutamyltransferase, though tests of liver function are normal until late stages. Imaging (particularly bile duct MRI or endoscopy) represents a useful diagnostic tool, as it may identify the classic strictured and dilated intrahepatic or extrahepatic bile ducts ${ }^{102}$. Performing a liver biopsy is generally not necessary for the diagnosis of PSC, except in the case of small-duct PSC which requires histologic examination. The natural history of this form is relatively benign and only a minority (12\%) of patients progress to classical PSC. The median timespan from diagnosis to liver-related death or liver transplantation is 18 years, and the prognosis is influenced by the onset of cholangiocarcinoma (CCA). CCA is more common with chronic biliary inflammation and difficult to distinguish from stricturing PSC ${ }^{101}$.

Association with rheumatic diseases

The association of PSC with IBD is well established. Nearly $70 \%$ of PSC cases also demonstrate findings of IBD ${ }^{104}$, frequently in mild asymptomatic forms, while $7 \%$ of IBD patients have PSC 105. Liver abnormalities are more frequently found in psoriatic patients, and this is typically attributed to non-alcoholic or alcoholic fatty liver ${ }^{106}$. However, in generalized pustular psoriasis, a less common form of psoriasis associated with extra-cutaneous manifestations, evidence for biliary involvement has been suggested, and neutrophilic cholangitis has been observed on liver biopsy, while magnetic resonance cholangiopancreatography showed features similar to those observed in PSC ${ }^{107 .}$ Autoantibodies 
In contrast to other autoimmune liver diseases, autoantibodies are of limited use in the diagnosis of PSC due to low sensitivity and specificity; only a limited percentage of patients (33\%) have positive p-ANCA ${ }^{108,109}$, for example. Only for PSC forms overlapping with AIH is serum ANA typically detected.

\section{Therapy}

The treatment of PSC is largely an unmet need and currently includes medical and endoscopic measures, short of liver transplantation ${ }^{110,111}$. UDCA has been investigated in several clinical trials, with conflicting results. Overall, the available evidence suggests that UDCA does not produce a substantial change in the course of PSC, despite remaining the most prescribed drug. However, it appears that high-dose UDCA ( $20 \mathrm{mg} / \mathrm{kg} /$ day) or norUDCA, a side chain-shortened homologue of UDCA, may reduce reduced biochemical indices of cholestasis ${ }^{112}$, the rate of progression, and might prevent the development of colon cancer (particularly in patients with UC/PSC overlap). Based on these inconclusive data, the use of UCDA in PSC varies widely, reflecting regional practice trends rather than science. Endoscopic interventions are indicated to treat complicated PSC through the dilation of short- and long-segment stenosis of the common bile duct and short-segment stenosis of the hepatic ducts near to the bifurcation. The treatment can be repeated over time once restenosis ensues and resulting survival rates are higher compared to patients not treated endoscopically. Biologics, mainly anti-TNF, have been used in PSC with concomitant IBD or rheumatic diseases with improvement in laboratory measurements ${ }^{113,114}$ but patients with PSC are generally excluded from IBD clinical trials, thus preventing firm conclusions regarding efficacy. Finally, PSC represents an important indication for liver transplantation since patients are younger than their counterparts with PBC. Recurrence of disease occurs in $20-40 \%$ of transplanted patients during prolonged follow-up. The ability of UDCA to prolong survival after disease recurrence remains a point on contention.

\section{Overlap syndromes.}

Commentato [L1]: Consider cutting out of place in the treatment section.

Commentato [CS2]: I would maintain this as it is a less known secret for PSC people 
Autoimmune liver diseases, similarly to rheumatic disease, may overlap and present with both hepatocellular and cholangiocellular patterns according to biochemical, histologic, and imagingbased analysis. When left without treatment, these patients show a more progressive course toward liver cirrhosis and failure. AIH-PBC overlap syndrome is found in $10 \%$ of adults with AIH whereas AIH-PSC overlap syndromes affects $6-8 \%$ of children, adolescents, and young adults with AIH; PBC-PSC overlap syndrome is exceptionally rare (Table 6). Besides overlaps, transitions are also possible in rare cases from $\mathrm{PBC}$ to $\mathrm{AIH}, \mathrm{AIH}$ to $\mathrm{PBC}$, or $\mathrm{AIH}$ to $\mathrm{PSC}{ }^{115}$.

AIH may have an atypical presentation with serum alkaline phosphatase elevation, AMA positivity, histologic features of bile duct injury/loss, or cholangiographic findings of focal biliary strictures and dilations. These manifestations characterize the overlap syndromes. The clues to an overlap syndrome consist of: (1) serum alkaline phosphatase $>2$-fold upper normal limit (ULN) at presentation, which is present in only $20 \%$ of AIH patients; (2) serum GGT > ULN unimproved or worsened during therapy; (3) AMA positivity; (4) histologic findings of bile duct injury or loss; (5) concurrent IBD; (6) corticosteroid treatment failure or incomplete response ${ }^{115}$.

Overlap features of PBC usually refers to simultaneous AIH in patients who have a diagnosis of AMA-positive PBC and not to patients with AIH who have coincidental AMA. AMA occur in about $5 \%$ of AIH patients in the absence of other biliary features ("serological overlap"), but may disappear or persist for decades without an evolution into PBC. Approximately $4 \%$ of PBC cases have simultaneous features of AIH. There are two different scoring systems that have been used to evaluate patients with PBC for simultaneous evidence of overlapping AIH: (1) the IAIH-G score; (2) looking for the presence of two of the three following features: (i) ALT activity 5 times upper limits of normal; (ii) IgG 2 times upper limits of normal and/or positive anti-SMA antibody; and overlap by (iii) liver biopsy with moderate or severe periportal or periseptal inflammation. A $\mathrm{PBC} / \mathrm{AIH}$ overlap syndrome may also refer to patients with sequential PBC followed by AIH, a condition occurring in $2.4 \%$ of cases. In these cases, the diagnosis of $\mathrm{PBC}$ with positive AMA occurs first and initially responds biochemically to UDCA therapy; subsequently, these patients 
present with clinical features of AIH, lose their AMA seropositivity, exhibit liver histology more typical of AIH, and respond to immunosuppressive therapy.

The term 'autoimmune cholangitis' was first coined to indicate AMA-negative PBC, possibly with serum ANA. More recently, a broader concept has emerged that includes: (1) serum ANA and/or SMA positivity and/or hyper-gammaglobulinemia; (2) serum AMA negativity by immunofluorescence; (3) biochemical and/or histological features of cholestatic and hepatocellular injury; and (4) exclusion of chronic viral, metabolic, or toxic liver disease. This definition possibly subsumes PBC with atypical presentation, small-duct PSC, idiopathic adulthood ductopenia, AIH with bile duct damage, concurrent $\mathrm{AIH}$ and small-duct PSC, and various transitional stages of the classic diseases. Consensus is still wanting on this issue, and standardization of diagnostic criteria for overlap syndromes is impeded by their uncommon occurrence in the setting of rare diseases.

\section{Osteometabolic consequences of chronic autoimmune liver disease.}

Advancements in the management of autoimmune liver diseases and cirrhosis complications have increased survival rates. However, longer survival rates, compounded by an aging population, have increased the risk of complications such as osteoporosis. Osteoporosis is associated with increased risk of fracture, which is two-fold higher in cirrhotic patients regardless of the liver disease etiology, and persists for years after liver transplantation ${ }^{116-119}$. Moreover, patients receiving glucocorticoids for AIH suffer an additional decrease in their bone mass.

According to the WHO definition, osteoporosis is diagnosed when bone density is less than 2.5 standard deviations below the peak value obtained from normal adults and adjusted for gender $(\mathrm{T}$ score) ${ }^{120}$. This definition is limited insofar as the threshold was established from studies of postmenopausal Caucasian women, rather than for patients with liver diseases. ${ }^{117}$ Therefore, some authors favor the term hepatic osteodystrophy, though this term also includes osteomalacia ${ }^{121}$. The mechanisms of cirrhosis-related osteoporosis are not fully understood, but it is generally recognized that the association between liver and bone diseases occurs due to an imbalance of bone 
turnover, which depends on the osteoblastic and osteoclastic activity ${ }^{122}$. In PBC, while the exact mechanism is also not completely understood, there is evidence that hormone balance, genetics, and cholestasis may contribute to determine bone structure and density changes. There has been conflicting evidence as to whether PBC-related osteoporosis results from diminished bone formation, which is a low-turnover state, or from increased bone resorption, which is a highturnover state. However, recent data suggest that bone formation is the culprit. Cirrhosis is associated with the reduction of specific growth factors, such as insulin-like growth factor 1, which impairs osteoblast function and bone formation; severe cholestasis can allow build-up of lithocholic acid, which inhibits osteoblast activity and can interfere with genetic regulation of bone formation 23.

The prevalence of osteoporosis in cirrhotic patients ranges from 12 to $70 \%$ according to the diagnostic modality and the liver disease etiology, with cholestatic diseases having a higher prevalence (20-44\%, even without an established diagnosis of cirrhosis). Moreover, fracture rates are increased in cholestatic diseases, varying from 13 to $22 \%$ according to the degree of liver function ${ }^{120}$.

Screening for osteoporosis is an important part of liver diseases management, and the guidelines indicate that patients with cirrhosis and PBC should be screened by an initial dual-energy X-ray absorptiometry (DXA) exam ${ }^{121}$. If initial results are normal, the DXA should be repeated every 1 to 3 years to assess significant bone loss, depending on the presence of additional risk factors (BMI less than $19 \mathrm{~kg} / \mathrm{m}^{2}$, heavy alcohol use, tobacco use, early menopause [<age 45 years], glucocorticoid use greater than 3 months, or family history of bone fragility fractures). ${ }^{121}$ In addition, BMD should be measured prior to liver transplantation.

Laboratory test are also helpful for evaluating bone metabolism, and include serum calcium, 25hydroxyvitamin D, phosphorus, osteocalcin, procollagen I carboxyterminal peptide, and parathyroid hormone (PTH), as well as urinary amino telopeptides of collagen I and urinary calcium. Routine 
monitoring of calcium, phosphorus, 25-hydroxyvitamin D, and PTH should be performed every 1 to 2 years ${ }^{123}$.

The treatment of osteoporosis is based on results obtained from trials assessing postmenopausal women, and few studies have included patients with liver diseases. Educational strategies include elimination of modifiable risk factors, such as smoke and alcohol cessation. Calcium and vitamin D supplementation is part of osteoporosis treatment. The total calcium intake should achieve a daily ingestion of 1.0 to 1.5 grams, preferably from diet to facilitate patients compliance ${ }^{120}$. Oral cholecaciferol (vitamin D3) can be prescribed at 1,000-4,000 IU per day or ergocalciferol (vitamin D2) at 50,000 IU per month. Given that calcitriol (1,25-dihydroxycholecalciferol or 1,25dihydroxyvitamin D3) is the final active vitamin D metabolite, it may represent a better treatment for liver disease patients. Calcitriol is usually prescribed as a daily oral dose of $800 \mathrm{IU}$ but can also be taken at a weekly dose of 5000 IU ${ }^{120}$. In PBC, calcium and vitamin D supplementation alone was inferior to hormonal replacement therapy in improving BMD. ${ }^{124,125}$ However, testing for vitamin D deficiency in cholestatic patients is useful to allow for appropriate supplementation, particularly in those taking cholestyramine, since this impairs vitamin D absorption ${ }^{116}$. Bisphosphonates represent the treatment of choice for osteoporosis in cirrhotic patients, because they attach to the bone surface and prevent resorption. ${ }^{126}$. The threshold of intervention in patients with liver disease, however, may be lower than in the general population, since in PBC T-scores below -1.5 are associated with a significant risk for vertebral fractures ${ }^{127}$. A recent randomized controlled trial for osteoporosis therapy in PBC patients showed that both monthly ibandronic acid and weekly alendronic acid improve bone mass and are comparable in safety, although adherence is higher with the monthly regimen ${ }^{128}$. Moreover, bisphosphonates and teriparatide reduce the risk of vertebral fractures in chronically glucocorticoid-treated patients ${ }^{129},{ }^{130}$. Hormone replacement therapy does not show any osteoporosis benefit for PBC patients, but its use is no longer contraindicated in chronic cholestasis ${ }^{131}$. Ultimately, treating PBC with UDCA may have beneficial effects also on the bone, since UDCA may increase osteoblast differentiation and 
mineralization, and neutralize the detrimental effects of lithocholic acid, bilirubin and sera from jaundiced patients on osteoblastic cells ${ }^{132}$.

\section{Concluding remarks.}

The coexistence of liver and rheumatic diseases represents an ideal example of the need for a interdisciplinary approach to individualize treatments. Indeed, patients with autoimmune liver diseases may be undertreated with anti-rheumatic drugs for liver safety concerns (as in the case of methotrexate), while liver test changes may raise unnecessary concerns. Furthermore, new biologics may be beneficial for more than one condition, though insufficient data exist from the hepatology perspective. Lastly, the rapid deterioration of bone health associated with chronic liver diseases is an obvious area of collaboration between gastroentology and rheumatology. With the current focus on personalized medicine, the coexistence of liver autoimmunity and rheumatic disease is an ideal area to develop and investigate the benefits of shared clinical practice. 
Tables and figures.

Table 1. Serum autoantibodies in autoimmune liver diseases.

\begin{tabular}{|c|c|c|}
\hline Antibody & Liver disease & Prevalence \\
\hline ANA & $\begin{array}{l}\text { AIH } \\
\text { PBC } \\
\text { PSC }\end{array}$ & $\begin{array}{l}\text { Homogeneous pattern } 34-58 \% \text {, speckled } 21-34 \% \\
\text { Nuclear pore complex targeting gp210 and nucleoporin p } 62 \text {, multiple } \\
\text { nuclear dots targeting Sp100-50-70\% } \\
20 \%\end{array}$ \\
\hline SMA & $\begin{array}{l}\text { AIH } \\
\text { PSC }\end{array}$ & $\begin{array}{l}81 \% \\
0-73 \%\end{array}$ \\
\hline LKM 1 & Type 2 AIH & \\
\hline LC 1 & Type 2 AIH & $50 \%$, only autoantibody in $10 \%$ of cases \\
\hline pANCA & $\begin{array}{l}\text { AIH } \\
\text { PSC }\end{array}$ & $-\overline{3} \%$ \\
\hline SLA/LP & $\mathrm{AIH}$ & $10-30 \%$ \\
\hline LKM 3 & Type 2 AIH & \\
\hline ASGPR & $\begin{array}{l}\text { AIH } \\
\text { PBC }\end{array}$ & $90 \%$ \\
\hline AMA & $\begin{array}{l}\text { AIH } \\
\text { PBC }\end{array}$ & $\begin{array}{l}9 \% \\
90-95 \%\end{array}$ \\
\hline ACA & $\begin{array}{l}\text { AIH } \\
\text { PBC }\end{array}$ & $\begin{array}{l}0-25 \% \\
9-30 \% \\
\end{array}$ \\
\hline Anti-dsDNA & $\begin{array}{l}\text { AIH } \\
\text { PBC }\end{array}$ & $\begin{array}{l}23-34 \% \\
0-22 \%\end{array}$ \\
\hline Rheumatoid Factor & $\mathrm{AIH}$ & $21 \%$ \\
\hline Anti-Histones & $\mathrm{AIH}$ & $35 \%$ \\
\hline Anti-Ro/SSA & $\begin{array}{l}\text { AIH } \\
\text { PBC }\end{array}$ & $\begin{array}{l}26 \% \\
10-28 \%\end{array}$ \\
\hline Anti-La/SSB & $\mathrm{AIH}$ & $4.3 \%$ \\
\hline Anti-CCP & $\mathrm{AIH}$ & $9 \%$ \\
\hline $\begin{array}{l}\text { Anti-cardiolipin } \\
\mathrm{Ig} / \mathrm{IgM}\end{array}$ & $\begin{array}{l}\text { AIH } \\
\text { PBC }\end{array}$ & $\begin{array}{l}40 \% \\
\text { IgM } 75 \%\end{array}$ \\
\hline Anti-nucleosome & $\begin{array}{l}\text { AIH } \\
\text { PBC } \\
\text { PSC }\end{array}$ & $\begin{array}{l}21.7 \% \\
14.2 \% \\
20 \%\end{array}$ \\
\hline Anti-RNP & $\begin{array}{l}\text { AIH } \\
\text { PSC }\end{array}$ & $\begin{array}{l}8.6 \% \\
5 \% \\
\end{array}$ \\
\hline Anti-Sm & $\mathrm{AIH}$ & $4.3 \%$ \\
\hline Anti-ribosomal P & $\begin{array}{l}\mathrm{AIH} \\
\mathrm{PSC}\end{array}$ & $\begin{array}{l}4.3 \% \\
5 \%\end{array}$ \\
\hline
\end{tabular}


Table 2. Revised Original Scoring System of the International Autoimmune Hepatitis Group ${ }^{34}$.

\begin{tabular}{|c|c|}
\hline Criteria & Points \\
\hline \multicolumn{2}{|l|}{ Sex } \\
\hline Male & 0 \\
\hline Female & +2 \\
\hline \multicolumn{2}{|l|}{ Ratio of ALP vs. AST/ALT } \\
\hline$>2.0$ & +3 \\
\hline $1.5-2.0$ & +2 \\
\hline $1.0-1.5$ & +1 \\
\hline$<1.0$ & 0 \\
\hline \multicolumn{2}{|l|}{ Autoantibodies (ANA, SMA, LKM1) titer } \\
\hline$>1: 80$ & +3 \\
\hline $1: 80$ & +2 \\
\hline 1:40 & +1 \\
\hline$<1: 40$ & 0 \\
\hline \multicolumn{2}{|l|}{ AMA } \\
\hline Positive & -4 \\
\hline Negative & 0 \\
\hline Seropositivity for other autoantibodies & +2 \\
\hline \multicolumn{2}{|l|}{ Viral hepatitis markers } \\
\hline Negative & +3 \\
\hline Positive & -3 \\
\hline \multicolumn{2}{|l|}{ History of drug use } \\
\hline Yes & -4 \\
\hline No & +1 \\
\hline \multicolumn{2}{|l|}{ Average alcohol consumption (g/day) } \\
\hline$<25$ & +2 \\
\hline$>60$ & -2 \\
\hline Presence of genetic factors (HLA, DR3 or DR4) & +1 \\
\hline Presence of other autoimmune disorders (thyroiditis, colitis, others) & +2 \\
\hline
\end{tabular}




\begin{tabular}{|l|l|}
\hline Liver histology & +3 \\
Interface hepatitis & +1 \\
Predominant lymphocytic infiltrate & +1 \\
Rosetting of liver cells & -5 \\
Biliary changes & -3 \\
Other changes & -3 \\
\hline Response to therapy & \\
Complete & +2 \\
\hline Relapse & +3 \\
\hline
\end{tabular}

A score $>15$ or $>17$ indicates a definite diagnosis of AIH pre- or post-treatment, respectively. On the other hand, scores between 10-15 and 12-17 indicate a probable diagnosis, pre- or post-therapy, respectively. AMA, anti-mitochondrial autoantibodies; LKM-1, anti-liver-kidney microsomal antibodies; SMA, anti-smooth-muscle antibodies. 
Table 3. Codified Diagnostic Criteria of the International Autoimmune Hepatitis Group ${ }^{34}$.

\begin{tabular}{|c|c|c|}
\hline Features & Definite & Probable \\
\hline Liver histology & $\begin{array}{l}\text { Interface hepatitis of moderate or } \\
\text { severe activity with or without } \\
\text { lobular hepatitis or central portal } \\
\text { bridging necrosis, but without biliary } \\
\text { lesions or well defined granulomas } \\
\text { or other prominent changes } \\
\text { suggestive of a different etiology }\end{array}$ & Same as for "definite" \\
\hline Serum biochemistry & $\begin{array}{l}\text { Any abnormality in serum } \\
\text { aminotransferases, especially if the } \\
\text { serum alkaline phosphatase is not } \\
\text { markedly elevated. Normal serum } \\
\text { concentrations of alpha antitrypsin, } \\
\text { copper and ceruolasmin }\end{array}$ & $\begin{array}{l}\text { Same as for "definite" but patients } \\
\text { with abnormal serum concentrations } \\
\text { of copper or ceruloplasmin may be } \\
\text { included, provided that Wilson } \\
\text { disease has been excluded by } \\
\text { appropriate investigations }\end{array}$ \\
\hline Serum immunoglobulins & $\begin{array}{l}\text { Total serum globulin or gamma } \\
\text { globulin or IgG concentrations } \\
\text { greater than } 1.5 \text { times the upper } \\
\text { normal limit }\end{array}$ & $\begin{array}{l}\text { Any elevation of serum globulin or } \\
\text { gamma globulin or IgG } \\
\text { concentrations above the upper } \\
\text { normal limit }\end{array}$ \\
\hline Serum autoantibodies & $\begin{array}{l}\text { Seropositivity for ANA, SMA or } \\
\text { anti-LKM1 antibodies at titers } \\
\text { greater than } 1: 80 \text {. Lower titers } \\
\text { (particularly of anti-LKM1) may be } \\
\text { significant in children. } \\
\text { Seronegativity for AMA }\end{array}$ & $\begin{array}{l}\text { Same as for "definite" but at titers of } \\
1: 40 \text { or greater. Patients who are } \\
\text { seronegative for these antibodies but } \\
\text { who are seropositive for other } \\
\text { antibodies may be included. }\end{array}$ \\
\hline Viral markers & $\begin{array}{l}\text { Seronegativity for markers of current } \\
\text { infection with hepatitis A, B and C } \\
\text { viruses }\end{array}$ & Same as for "definite" \\
\hline Other etiological factors & $\begin{array}{l}\text { Average alcohol consumption less } \\
\text { than } 25 \mathrm{~g} / \text { day } \\
\text { No history of recent use of known } \\
\text { hepatotoxic drugs }\end{array}$ & $\begin{array}{l}\text { Alcohol consumption less than } \\
50 \mathrm{~g} / \text { day and no recent use of known } \\
\text { hepatotoxic drugs } \\
\text { Patients who have consumed larger } \\
\text { amounts of alcohol or who have } \\
\text { recently taken potentially } \\
\text { hepatotoxic drugs may be included, } \\
\text { if there is clear evidence of } \\
\text { continuing liver damage after } \\
\text { abstinence from alcohol or } \\
\text { withdrawal of the drug }\end{array}$ \\
\hline
\end{tabular}


Table 4. Treatment of autoimmune liver diseases with rheumatic DMARDs and biologic therapy

\begin{tabular}{|c|c|c|}
\hline Drug & Dosage & Safety \\
\hline \multicolumn{3}{|l|}{ Autoimmune hepatitis } \\
\hline Prednisone & $\begin{array}{l}\text { First-line treatment }(1 \mathrm{mg} / \mathrm{kg} / \mathrm{day} \text {, } \\
\text { maximum } 60 \mathrm{mg} / \text { day in } \\
\text { monotherapy) }\end{array}$ & $\begin{array}{l}\text { Acute: hyperglycemia, high blood } \\
\text { pressure } \\
\text { Chronic: diabetes, osteoporosis, } \\
\text { glaucoma, cataract }\end{array}$ \\
\hline Azathioprine & $\begin{array}{l}\text { Induction therapy }(1-2 \mathrm{mg} / \mathrm{kg} / \text { day, } \\
\text { maximum } 200 \mathrm{mg} / \text { day) in } \\
\text { combination with prednisone ( } 30 \\
\mathrm{mg} / \text { day) } \\
\text { Maintenance therapy }(50 \mathrm{mg} / \text { day or } \\
\text { up to } 2 \mathrm{mg} / \mathrm{kg} / \text { day) }\end{array}$ & $\begin{array}{l}\text { Leukopenia, liver toxicity, infections, } \\
\text { nausea and vomiting }\end{array}$ \\
\hline Mycophenolate mofetil & Second-line ( 1.5 to $2 \mathrm{~g}$ daily) & $\begin{array}{l}\text { Infections, nausea and vomiting, } \\
\text { cytopenia, contraindicated in pregnancy }\end{array}$ \\
\hline Cyclosporine & Refractory cases ( $2-5 \mathrm{mg} / \mathrm{kg}$ daily) & $\begin{array}{l}\text { Hypertension, increased serum } \\
\text { creatinine, hirsutism }\end{array}$ \\
\hline Methotrexate & Refractory cases: Case reports & $\begin{array}{l}\text { Liver toxicity, infections, } \\
\text { contraindicated in pregnancy }\end{array}$ \\
\hline Infliximab & Refractory cases: Case reports & $\begin{array}{l}\text { Liver toxicity, induction of AIH, } \\
\text { contraindicated in pregnancy }\end{array}$ \\
\hline Rituximab & Refractory cases: Case reports & contraindicated in pregnancy \\
\hline \multicolumn{3}{|c|}{ Primary biliary cholangitis } \\
\hline Azathioprine & $\begin{array}{l}\text { Refractory cases }(50 \mathrm{mg} / \text { day })+ \\
\text { prednisone }(30 \mathrm{mg} / \text { day })+\text { UDCA }\end{array}$ & $\begin{array}{l}\text { Leukopenia, liver toxicity, infections, } \\
\text { nausea and vomiting }\end{array}$ \\
\hline Cyclosporine & Refractory cases & $\begin{array}{l}\text { Hypertension, increased serum } \\
\text { creatinine, hirsutism }\end{array}$ \\
\hline Methotrexate & $\begin{array}{l}\text { Refractory cases }(0.25 \mathrm{mg} / \mathrm{kg} / \text { week } \\
\text { per os })\end{array}$ & $\begin{array}{l}\text { Liver toxicity, infections, } \\
\text { contraindicated in pregnancy }\end{array}$ \\
\hline Mycophenolate mofetil & Refractory cases (1-2 mg/day) & $\begin{array}{l}\text { Infections, nausea and vomiting, } \\
\text { cytopenia, contraindicated in pregnancy }\end{array}$ \\
\hline Colchicine & Refractory cases (1.2mg/day) & Diarrhea, myelosuppression \\
\hline Ustekinumab & $\begin{array}{l}\text { Under evaluation ( } 90 \mathrm{mg} \text { sc weeks } 0 \\
-4 \text { and then every } 8 \text { weeks) }\end{array}$ & Infections, contraindicated in pregnancy \\
\hline Abatacept & Under evaluation & - \\
\hline \multicolumn{3}{|c|}{ Primary sclerosing cholangitis } \\
\hline Cyclosporine & Refractory cases & $\begin{array}{l}\text { Hypertension, increased serum } \\
\text { creatinine, hirsutism }\end{array}$ \\
\hline Methotrexate & Refractory cases & $\begin{array}{l}\text { Liver toxicity, infections, } \\
\text { contraindicated in pregnancy }\end{array}$ \\
\hline
\end{tabular}

UDCA: ursodeoxycholic acid 
Table 5. Diagnostic criteria for Primary Biliary Cholangitis (PBC). Diagnosis is made in the presence of at least 2 out of 3 of the criteria.

\begin{tabular}{|l|}
\hline Parameters \\
\hline Elevated ALP $>2 \times$ ULN or GGT $>5 \times$ ULN \\
\hline AMA positivity \\
\hline Chronic granulomatous cholangitis at liver biopsy \\
\hline
\end{tabular}

ALP: alkaline phosphatase; ULN: upper limit of normal; GGT: $\gamma$-glutamyltransferase; AMA: antimitochondrial antibodies. 
Table 6. Diagnostic features of overlap syndromes.

\begin{tabular}{|c|c|c|}
\hline Overlap Syndrome & Laboratory features & Histologic findings \\
\hline $\mathrm{AIH} / \mathrm{PBC}$ & $\begin{array}{l}\text { ANA or SMA } \\
\text { Hypergammaglobulinemia } \\
\text { Serum IgG increased } \\
\text { Marked serum AST/ALT abnormalities } \\
\text { AP or GGT > ULN } \\
\text { AMA positive }\end{array}$ & $\begin{array}{l}\text { Interface hepatitis } \\
\text { Lymphocytic portal infiltrate } \\
\text { Portal plasma cells } \\
\text { Destructive cholangitis }\end{array}$ \\
\hline $\begin{array}{l}\mathrm{AIH} / \mathrm{PBC} \\
\text { (Paris criteria) }\end{array}$ & $\begin{array}{l}\text { AIH features ( } 2 \text { of } 3 \text { ): } \\
\text { Serum ALT } \geq 5 \text {-fold ULN } \\
\text { Serum IgG } \geq 2 \text {-fold ULN or } \\
\text { SMA present } \\
\text { Interface hepatitis } \\
\text { PBC features ( } 2 \text { of } 3 \text { ): } \\
\text { Serum AP } \geq 2 \text {-fold ULN or GGT } \\
\geq 5 \text {-fold ULN } \\
\text { AMA positive } \\
\text { Florid duct lesions }\end{array}$ & $\begin{array}{l}\text { Interface hepatitis (moderate } \\
\text { to severe) } \\
\text { Destructive cholangitis }\end{array}$ \\
\hline $\mathrm{AIH} / \mathrm{PSC}$ & $\begin{array}{l}\text { ANA or SMA } \\
\text { Hypergammaglobulinemia } \\
\text { Serum IgG increased } \\
\text { Marked serum AST/ALT abnormalities } \\
\text { Focal biliary strictures and dilations }\end{array}$ & $\begin{array}{l}\text { Lymphocytic portal infiltrate } \\
\text { Ductular proliferation } \\
\text { Periductular fibrosis } \\
\text { Portal edema } \\
\text { Cholate stasis } \\
\text { Fibrous obliterative } \\
\text { cholangitis (rare) } \\
\text { Ductopenia } \\
\text { Increased stainable hepatic } \\
\text { copper }\end{array}$ \\
\hline $\begin{array}{l}\text { AIH and undefined } \\
\text { cholestatic } \\
\text { syndrome }\end{array}$ & $\begin{array}{l}\text { ANA or SMA } \\
\text { Hypergammaglobulinemia } \\
\text { Serum IgG increased } \\
\text { Marked serum AST/ALT abnormalities } \\
\text { AMA negative } \\
\text { No biliary strictures and dilations }\end{array}$ & $\begin{array}{l}\text { Interface hepatitis plus at } \\
\text { least: } \\
\text { Destructive cholangitis } \\
\text { Periductular fibrosis } \\
\text { Ductopenia } \\
\text { Portal edema }\end{array}$ \\
\hline
\end{tabular}




\section{References.}

1. Cowling DC, Mackay IR, Taft LI. Lupoid hepatitis. Lancet. 1956;271(6957):1323-1326.

2. Adiga A, Nugent K. Lupus Hepatitis and Autoimmune Hepatitis (Lupoid Hepatitis). Am J Med Sci. 2017;353(4):329-335.

3. Doherty DG. Immunity, tolerance and autoimmunity in the liver: A comprehensive review. J Autoimmun. 2016;66:60-75.

4. Liberal R, Selmi C, Gershwin ME. Diego and Giorgina Vergani: The two hearts of translational autoimmunity. J Autoimmun. 2016;66:1-6.

5. Molinaro A, Marschall HU. Why Doesn't Primary Biliary Cholangitis Respond to Immunosuppressive Medications? Curr Hepatol Rep. 2017;16(2):119-123.

6. Gatselis NK, Zachou K, Lygoura V, et al. Geoepidemiology, clinical manifestations and outcome of primary biliary cholangitis in Greece. Eur J Intern Med. 2017;42:81-88.

7. Kim BH, Choi HY, Ki M, Kim KA, Jang ES, Jeong SH. Population-based prevalence, incidence, and disease burden of autoimmune hepatitis in South Korea. PLoS One. 2017;12(8):e0182391.

8. Ji J, Sundquist J, Sundquist K. Gender-specific incidence of autoimmune diseases from national registers. $J$ Autoimmun. 2016;69:102-106.

9. Ma WT, Chang C, Gershwin ME, Lian ZX. Development of autoantibodies precedes clinical manifestations of autoimmune diseases: A comprehensive review. J Autoimmun. 2017.

10. Toh BH. Diagnostic autoantibodies for autoimmune liver diseases. Clin Transl Immunology. 2017;6(5):e139.

11. Watad A, Azrielant S, Bragazzi NL, et al. Seasonality and autoimmune diseases: The contribution of the four seasons to the mosaic of autoimmunity. J Autoimmun. 2017;82:13-30. 12. Murray-Lyon IM, Thompson RP, Ansell ID, Williams R. Scleroderma and primary biliary cirrhosis. Br Med J. 1970;3(5717):258-259. 
13. Clarke AK, Galbraith RM, Hamilton EB, Williams R. Rheumatic disorders in primary biliary cirrhosis. Ann Rheum Dis. 1978;37(1):42-47.

14. Morgan MY. Primary biliary cirrhosis, scleroderma and keratoconjunctivitis sicca. Proc $R$ Soc Med. 1973;66(11):1112.

15. Selmi C, Meroni PL, Gershwin ME. Primary biliary cirrhosis and Sjogren's syndrome: autoimmune epithelitis. J Autoimmun. 2012;39(1-2):34-42.

16. Sirotti S, Generali E, Ceribelli A, Isailovic N, De Santis M, Selmi C. Personalized medicine in rheumatology: the paradigm of serum autoantibodies. Auto Immun Highlights. 2017;8(1):10.

17. Selmi C, Bowlus CL, Gershwin ME, Coppel RL. Primary biliary cirrhosis. Lancet. 2011;377(9777):1600-1609.

18. Cropley A, Weltman M. The use of immunosuppression in autoimmune hepatitis: A current literature review. Clin Mol Hepatol. 2017;23(1):22-26.

19. Hirschfield GM, Gershwin ME, Strauss R, et al. Ustekinumab for patients with primary biliary cholangitis who have an inadequate response to ursodeoxycholic acid: A proof-of-concept study. Hepatology. 2016;64(1):189-199.

20. Chimenti MS, Talamonti M, Novelli L, et al. Long-term ustekinumab therapy of psoriasis in patients with coexisting rheumatoid arthritis and Sjogren syndrome. Report of two cases and review of literature. J Dermatol Case Rep. 2015;9(3):71-75.

21. Card TR, Langan SM, Chu TP. Extra-Gastrointestinal Manifestations of Inflammatory Bowel Disease May Be Less Common Than Previously Reported. Dig Dis Sci. 2016;61(9):26192626.

22. Whittier X, Saag KG. Glucocorticoid-induced Osteoporosis. Rheum Dis Clin North Am. 2016;42(1):177-189, x.

23. Glass LM, Su GL. Metabolic Bone Disease in Primary Biliary Cirrhosis. Gastroenterol Clin North Am. 2016;45(2):333-343. 
24. Imam MH, Talwalkar JA, Lindor KD. Clinical management of autoimmune biliary diseases. J Autoimmun. 2013;46:88-96.

25. Liberal R, Krawitt EL, Vierling JM, Manns MP, Mieli-Vergani G, Vergani D. Cutting edge issues in autoimmune hepatitis. $J$ Autoimmun. 2016;75:6-19.

26. Hardtke-Wolenski M, Dywicki J, Fischer K, et al. The influence of genetic predisposition and autoimmune hepatitis inducing antigens in disease development. J Autoimmun. 2017;78:39-45.

27. Krawitt EL. Autoimmune hepatitis. N Engl J Med. 2006;354(1):54-66.

28. Jepsen P, Gronbaek L, Vilstrup H. Worldwide Incidence of Autoimmune Liver Disease. Dig Dis. 2015;33 Suppl 2:2-12.

29. Floreani A, Liberal R, Vergani D, Mieli-Vergani G. Autoimmune hepatitis: Contrasts and comparisons in children and adults - a comprehensive review. $J$ Autoimmun. 2013;46:7-16.

30. Wang Q, Yang F, Miao Q, Krawitt EL, Gershwin ME, Ma X. The clinical phenotypes of autoimmune hepatitis: A comprehensive review. J Autoimmun. 2016;66:98-107.

31. Liberal R, Grant CR, Mieli-Vergani G, Vergani D. Autoimmune hepatitis: a comprehensive review. J Autoimmun. 2013;41:126-139.

32. Webb GJ, Hirschfield GM. Using GWAS to identify genetic predisposition in hepatic autoimmunity. J Autoimmun. 2016;66:25-39.

33. Alvarez F, Berg PA, Bianchi FB, et al. International Autoimmune Hepatitis Group Report: review of criteria for diagnosis of autoimmune hepatitis. J Hepatol. 1999;31(5):929-938.

34. Manns MP, Czaja AJ, Gorham JD, et al. Diagnosis and management of autoimmune hepatitis. Hepatology. 2010;51(6):2193-2213.

35. Czaja AJ. Performance parameters of the diagnostic scoring systems for autoimmune hepatitis. Hepatology. 2008;48(5):1540-1548.

36. Wong GW, Heneghan MA. Association of Extrahepatic Manifestations with Autoimmune Hepatitis. Dig Dis. 2015;33 Suppl 2:25-35. 
37. van Gerven NM, Verwer BJ, Witte BI, et al. Epidemiology and clinical characteristics of autoimmune hepatitis in the Netherlands. Scand J Gastroenterol. 2014;49(10):1245-1254.

38. Muratori P, Lenzi M, Cassani F, Lalanne C, Muratori L. Diagnostic approach to autoimmune hepatitis. Expert Rev Clin Immunol. 2017;13(8):769-779.

39. Czaja AJ. Autoimmune liver disease and rheumatic manifestations. Curr Opin Rheumatol. 2007;19(1):74-80.

40. Borman MA, Urbanski S, Swain MG. Anti-TNF-induced autoimmune hepatitis. J Hepatol. 2014;61(1):169-170.

41. French JB, Bonacini M, Ghabril M, Foureau D, Bonkovsky HL. Hepatotoxicity Associated with the Use of Anti-TNF-alpha Agents. Drug Saf. 2016;39(3):199-208.

42. Rodrigues S, Lopes S, Magro F, et al. Autoimmune hepatitis and anti-tumor necrosis factor alpha therapy: A single center report of 8 cases. World J Gastroenterol. 2015;21(24):7584-7588.

43. Sebode M, Hartl J, Vergani D, Lohse AW, International Autoimmune Hepatitis G.

Autoimmune hepatitis: From current knowledge and clinical practice to future research agenda.

Liver Int. 2017.

44. Liberal R, Mieli-Vergani G, Vergani D. Clinical significance of autoantibodies in autoimmune hepatitis. J Autoimmun. 2013;46:17-24.

45. Cancado EL, Abrantes-Lemos CP, Terrabuio DR. The importance of autoantibody detection in autoimmune hepatitis. Front Immunol. 2015;6:222.

46. Muratori L, Deleonardi G, Lalanne C, et al. Autoantibodies in Autoimmune Hepatitis. Dig Dis. 2015;33 Suppl 2:65-69.

47. Selmi C, Ceribelli A, Generali E, et al. Serum antinuclear and extractable nuclear antigen antibody prevalence and associated morbidity and mortality in the general population over 15 years. Autoimmun Rev. 2016;15(2):162-166. 
48. Mullin S, Rabah R, Malas S, Bitar A. Autoimmune Hepatitis Type 2 Associated With Positive Antimitochondrial Antibodies: An Overlap Syndrome? Clin Pediatr (Phila). 2016;55(5):479-482.

49. Liaskos C, Rigopoulou E, Zachou K, et al. Prevalence and clinical significance of anticardiolipin antibodies in patients with type 1 autoimmune hepatitis. J Autoimmun. $2005 ; 24(3): 251-260$.

50. Linares P, Vivas S, Olcoz JL. Autoimmune hepatitis associated with the antiphospholipid syndrome and ulcerative colitis. Eur J Intern Med. 2005;16(5):376.

51. Czaja AJ. Autoantibodies as prognostic markers in autoimmune liver disease. Dig Dis Sci. 2010;55(8):2144-2161.

52. Czaja AJ, Ming C, Shirai M, Nishioka M. Frequency and significance of antibodies to histones in autoimmune hepatitis. J Hepatol. 1995;23(1):32-38.

53. Czaja AJ, Morshed SA, Parveen S, Nishioka M. Antibodies to single-stranded and doublestranded DNA in antinuclear antibody-positive type 1-autoimmune hepatitis. Hepatology. 1997;26(3):567-572.

54. Czaja AJ. Evolving paradigm of treatment for autoimmune hepatitis. Expert Rev Clin Immunol. 2017;13(8):781-798.

55. Haridy J, Nicoll A, Sood S. Methotrexate Therapy for Autoimmune Hepatitis. Clin Gastroenterol Hepatol. 2017.

56. Efe C, Hagstrom H, Ytting H, et al. Efficacy and Safety of Mycophenolate Mofetil and Tacrolimus as Second-line Therapy for Patients with Autoimmune Hepatitis. Clin Gastroenterol Hepatol. 2017.

57. Weiler-Normann C, Schramm C, Quaas A, et al. Infliximab as a rescue treatment in difficult-to-treat autoimmune hepatitis. J Hepatol. 2013;58(3):529-534. 
58. Burak KW, Swain MG, Santodomingo-Garzon T, et al. Rituximab for the treatment of patients with autoimmune hepatitis who are refractory or intolerant to standard therapy. Can J Gastroenterol. 2013;27(5):273-280.

59. Than NN, Jeffery HC, Oo YH. Autoimmune Hepatitis: Progress from Global Immunosuppression to Personalised Regulatory T Cell Therapy. Can J Gastroenterol Hepatol. 2016;2016:7181685.

60. Schramm C, Bubenheim M, Adam R, et al. Primary liver transplantation for autoimmune hepatitis: a comparative analysis of the European Liver Transplant Registry. Liver Transpl. 2010;16(4):461-469.

61. Cho CW, Kwon CHD, Kim JM, Choi GS, Joh JW, Lee SK. Comparative Analysis of the Clinical Outcomes of Liver Transplantation for Probable and Definite Auto-immune Hepatitis by International Diagnostic Scoring Criteria. Transplant Proc. 2017;49(5):1126-1128.

62. Neuberger J. An update on liver transplantation: A critical review. J Autoimmun. 2016;66:51-59.

63. Kerkar N, Yanni G. 'De novo' and 'recurrent' autoimmune hepatitis after liver transplantation: A comprehensive review. J Autoimmun. 2016;66:17-24.

64. Shuai Z, Wang J, Badamagunta M, et al. The fingerprint of antimitochondrial antibodies and the etiology of primary biliary cholangitis. Hepatology. 2017;65(5):1670-1682.

65. Webb GJ, Siminovitch KA, Hirschfield GM. The immunogenetics of primary biliary cirrhosis: A comprehensive review. J Autoimmun. 2015;64:42-52.

66. Lleo A, Jepsen P, Morenghi E, et al. Evolving Trends in Female to Male Incidence and Male Mortality of Primary Biliary Cholangitis. Sci Rep. 2016;6:25906.

67. Beuers U, Gershwin ME, Gish RG, et al. Changing Nomenclature for PBC: From 'Cirrhosis' to 'Cholangitis'. Clin Gastroenterol Hepatol. 2015;13(11):1867-1869.

68. Floreani A, Tanaka A, Bowlus C, Gershwin ME. Geoepidemiology and changing mortality in primary biliary cholangitis. $J$ Gastroenterol. 2017;52(6):655-662. 
69. Invernizzi P, Floreani A, Carbone M, et al. Primary Biliary Cholangitis: advances in management and treatment of the disease. Dig Liver Dis. 2017;49(8):841-846.

70. Floreani A, Franceschet I, Cazzagon N, et al. Extrahepatic autoimmune conditions associated with primary biliary cirrhosis. Clin Rev Allergy Immunol. 2015;48(2-3):192-197.

71. Mills P, MacSween RN, Watkinson G. Arthritis and primary biliary cirrhosis. $\mathrm{Br}$ Med J. 1977;2(6096):1224.

72. Parikh-Patel A, Gold E, Mackay IR, Gershwin ME. The geoepidemiology of primary biliary cirrhosis: contrasts and comparisons with the spectrum of autoimmune diseases. Clin Immunol. 1999;91(2):206-218.

73. Kung YY, Tsai CY, Tsai YY, Tsai ST, Yu CL. Enthesopathy in a case of primary biliary cirrhosis with positive HLA-B27. Clin Exp Rheumatol. 1997;15(6):708-709.

74. Philips C, Paramaguru R, Indiran DA, Augustine P. Dermatitis Herpetiformis as the Initial Presentation of Primary Biliary Cholangitis in a Male with Gluten Sensitivity. Cureus. 2017;9(5):e1247.

75. Terziroli Beretta-Piccoli B, Guillod C, Marsteller I, et al. Primary Biliary Cholangitis Associated with Skin Disorders: A Case Report and Review of the Literature. Arch Immunol Ther Exp (Warsz). 2017;65(4):299-309.

76. Tsianos EV, Hoofnagle JH, Fox PC, et al. Sjogren's syndrome in patients with primary biliary cirrhosis. Hepatology. 1990;11(5):730-734.

77. Uddenfeldt P, Danielsson A, Forssell A, Holm M, Ostberg Y. Features of Sjogren's syndrome in patients with primary biliary cirrhosis. J Intern Med. 1991;230(5):443-448.

78. Liberal R, Grant CR, Sakkas L, Bizzaro N, Bogdanos DP. Diagnostic and clinical significance of anti-centromere antibodies in primary biliary cirrhosis. Clin Res Hepatol Gastroenterol. 2013;37(6):572-585. 
79. Gershwin ME, Mackay IR, Sturgess A, Coppel RL. Identification and specificity of a cDNA encoding the $70 \mathrm{kd}$ mitochondrial antigen recognized in primary biliary cirrhosis. $J$ Immunol. $1987 ; 138(10): 3525-3531$

80. Bowlus CL, Gershwin ME. The diagnosis of primary biliary cirrhosis. Autoimmun Rev. 2014;13(4-5):441-444.

81. Leung PS, Wang J, Naiyanetr P, et al. Environment and primary biliary cirrhosis: electrophilic drugs and the induction of AMA. J Autoimmun. 2013;41:79-86.

82. Chantran Y, Ballot E, Johanet C. Autoantibodies in primary biliary cirrhosis: antimitochondrial autoantibodies. Clin Res Hepatol Gastroenterol. 2013;37(4):431-433.

83. Liu H, Norman GL, Shums Z, et al. PBC screen: an IgG/IgA dual isotype ELISA detecting multiple mitochondrial and nuclear autoantibodies specific for primary biliary cirrhosis. $J$ Autoimmun. 2010;35(4):436-442.

84. Rigopoulou EI, Davies ET, Bogdanos DP, et al. Antimitochondrial antibodies of immunoglobulin G3 subclass are associated with a more severe disease course in primary biliary cirrhosis. Liver Int. 2007;27(9):1226-1231.

85. Worman HJ, Courvalin JC. Antinuclear antibodies specific for primary biliary cirrhosis. Autoimmun Rev. 2003;2(4):211-217.

86. Powell FC, Winkelmann RK, Venencie-Lemarchand F, Spurbeck JL, Schroeter AL. The anticentromere antibody: disease specificity and clinical significance. Mayo Clin Proc.

1984;59(10):700-706.

87. Chan HL, Lee YS, Hong HS, Kuo TT. Anticentromere antibodies (ACA): clinical distribution and disease specificity. Clin Exp Dermatol. 1994;19(4):298-302.

88. Tovoli F, Granito A, Giampaolo L, et al. Nailfold capillaroscopy in primary biliary cirrhosis: a useful tool for the early diagnosis of scleroderma. J Gastrointestin Liver Dis. 2014;23(1):39-43. 
89. Guillen-Del Castillo A, Callejas-Moraga EL, Garcia G, et al. High sensitivity and negative predictive value of the DETECT algorithm for an early diagnosis of pulmonary arterial hypertension in systemic sclerosis: application in a single center. Arthritis Res Ther. 2017;19(1):135.

90. Agmon-Levin N, Shapira Y, Selmi C, et al. A comprehensive evaluation of serum autoantibodies in primary biliary cirrhosis. J Autoimmun. 2010;34(1):55-58.

91. von Landenberg P, Baumgartner M, Schoelmerich J, Lackner KJ, Klein R. Clinical relevance of antiphospholipid antibodies in primary biliary cirrhosis. Ann N Y Acad Sci. 2005;1051:20-28.

92. Floreani A, Mangini C. Primary biliary cholangitis: Old and novel therapy. Eur J Intern Med. 2017.

93. Bonis PA, Kaplan MM. Low-dose methotrexate in primary biliary cirrhosis.

Gastroenterology. 1999;117(6):1510-1513.

94. Selmi C, Generali E, Cantarini L. Tumor Necrosis Factor-Alpha at the Crossroad between Rheumatoid Arthritis and Autoimmune Cholangitis. Isr Med Assoc J. 2015;17(2):112-113.

95. Del Ross T, Ruffatti A, Floreani A, Hoxha A, Punzi L. The efficacy of adalimumab in psoriatic arthritis concomitant to overlapping primary biliary cholangitis and primary sclerosing cholangitis: a case report. BMC Musculoskelet Disord. 2016;17(1):485.

96. Wang YH, Yang W, Yang JB, et al. Systems biologic analysis of T regulatory cells genetic pathways in murine primary biliary cirrhosis. J Autoimmun. 2015;59:26-37.

97. Mousa HS, Carbone M, Malinverno F, Ronca V, Gershwin ME, Invernizzi P. Novel therapeutics for primary biliary cholangitis: Toward a disease-stage-based approach. Autoimmun Rev. 2016;15(9):870-876.

98. Yang XC, Fujino M, Cai SJ, Li SW, Liu C, Li XK. Genetic Polymorphisms of Cytotoxic TLymphocyte Antigen 4 in Primary Biliary Cholangitis: A Meta-Analysis. J Immunol Res.

2017;2017:5295164. 
99. Dhirapong A, Yang GX, Nadler S, et al. Therapeutic effect of cytotoxic T lymphocyte antigen 4/immunoglobulin on a murine model of primary biliary cirrhosis. Hepatology.

2013;57(2):708-715.

100. Sarkar S, Bowlus CL. Primary Sclerosing Cholangitis: Multiple Phenotypes, Multiple Approaches. Clin Liver Dis. 2016;20(1):67-77.

101. Gidwaney NG, Pawa S, Das KM. Pathogenesis and clinical spectrum of primary sclerosing cholangitis. World J Gastroenterol. 2017;23(14):2459-2469.

102. Bowlus CL. Cutting edge issues in primary sclerosing cholangitis. Clin Rev Allergy Immunol. 2011;41(2):139-150.

103. Yimam KK, Bowlus CL. Diagnosis and classification of primary sclerosing cholangitis. Autoimmun Rev. 2014;13(4-5):445-450.

104. Palmela C, Peerani F, Castaneda D, Torres J, Itzkowitz SH. Inflammatory Bowel Disease and Primary Sclerosing Cholangitis: A Review of the Phenotype and Associated Specific Features. Gut Liver. 2017.

105. Vavricka SR, Schoepfer A, Scharl M, Lakatos PL, Navarini A, Rogler G. Extraintestinal Manifestations of Inflammatory Bowel Disease. Inflamm Bowel Dis. 2015;21(8):1982-1992.

106. Xu X, Su L, Gao Y, Ding Y. The Prevalence of Nonalcoholic Fatty Liver Disease and Related Metabolic Comorbidities Was Associated with Age at Onset of Moderate to Severe Plaque Psoriasis: A Cross-Sectional Study. PLoS One. 2017;12(1):e0169952.

107. Viguier M, Allez M, Zagdanski AM, et al. High frequency of cholestasis in generalized pustular psoriasis: Evidence for neutrophilic involvement of the biliary tract. Hepatology.

2004;40(2):452-458.

108. Seibold F, Slametschka D, Gregor M, Weber P. Neutrophil autoantibodies: a genetic marker in primary sclerosing cholangitis and ulcerative colitis. Gastroenterology. 1994;107(2):532-536. 109. Metcalf JV, Mitchison HC, Palmer JM, Jones DE, Bassendine MF, James OF. Natural history of early primary biliary cirrhosis. Lancet. 1996;348(9039):1399-1402. 
110. Lazaridis KN, LaRusso NF. Primary Sclerosing Cholangitis. N Engl J Med.

2016;375(25):2501-2502.

111. Saffioti F, Gurusamy KS, Hawkins N, et al. Pharmacological interventions for primary sclerosing cholangitis: an attempted network meta-analysis. Cochrane Database Syst Rev. 2017;3:CD011343.

112. Fickert P, Hirschfield GM, Denk G, et al. norUrsodeoxycholic acid improves cholestasis in primary sclerosing cholangitis. J Hepatol. 2017.

113. Franceschet I, Cazzagon N, Del Ross T, D'Inca R, Buja A, Floreani A. Primary sclerosing cholangitis associated with inflammatory bowel disease: an observational study in a Southern Europe population focusing on new therapeutic options. Eur J Gastroenterol Hepatol. 2016;28(5):508-513.

114. Olmedo Martin RV, Amo Trillo V, Gonzalez Grande R, Jimenez Perez M. Efficacy and safety of vedolizumab as a treatment option for moderate to severe refractory ulcerative colitis in two patients after liver transplant due to primary sclerosing cholangitis. Rev Esp Enferm Dig. $2017 ; 109$.

115. Czaja AJ, Carpenter HA. Autoimmune Hepatitis Overlap Syndromes and Liver Pathology. Gastroenterol Clin North Am. 2017;46(2):345-364.

116. Guanabens N, Pares A. Management of osteoporosis in liver disease. Clin Res Hepatol Gastroenterol. 2011;35(6-7):438-445.

117. Luxon BA. Bone disorders in chronic liver diseases. Curr Gastroenterol Rep. $2011 ; 13(1): 40-48$.

118. Giannini S, Nobile M, Ciuffreda M, et al. Long-term persistence of low bone density in orthotopic liver transplantation. Osteoporos Int. 2000;11(5):417-424.

119. Zhao J, Li W, Cao J, Liang C, Yao DK. Association between primary biliary cholangitis and fracture: A meta-analysis. Clin Res Hepatol Gastroenterol. 2017. 
120. Santos LA, Romeiro FG. Diagnosis and Management of Cirrhosis-Related Osteoporosis. Biomed Res Int. 2016;2016:1423462.

121. Leslie WD, Bernstein CN, Leboff MS, American Gastroenterological Association Clinical Practice C. AGA technical review on osteoporosis in hepatic disorders. Gastroenterology. 2003;125(3):941-966.

122. Lopez-Larramona G, Lucendo AJ, Gonzalez-Castillo S, Tenias JM. Hepatic osteodystrophy: An important matter for consideration in chronic liver disease. World J Hepatol. 2011;3(12):300307.

123. Pares A, Guanabens N. Treatment of bone disorders in liver disease. J Hepatol. 2006;45(3):445-453.

124. Pereira SP, O'Donohue J, Moniz C, et al. Transdermal hormone replacement therapy improves vertebral bone density in primary biliary cirrhosis: results of a 1-year controlled trial. Aliment Pharmacol Ther. 2004;19(5):563-570.

125. Crippin JS, Jorgensen RA, Dickson ER, Lindor KD. Hepatic osteodystrophy in primary biliary cirrhosis: effects of medical treatment. Am J Gastroenterol. 1994;89(1):47-50.

126. Yurci A, Kalkan AO, Ozbakir O, et al. Efficacy of different therapeutic regimens on hepatic osteodystrophy in chronic viral liver disease. Eur J Gastroenterol Hepatol. 2011;23(12):1206-1212. 127. Guanabens N, Cerda D, Monegal A, et al. Low bone mass and severity of cholestasis affect fracture risk in patients with primary biliary cirrhosis. Gastroenterology. 2010;138(7):2348-2356.

128. Guanabens N, Monegal A, Cerda D, et al. Randomized trial comparing monthly ibandronate and weekly alendronate for osteoporosis in patients with primary biliary cirrhosis. Hepatology. 2013;58(6):2070-2078.

129. Allen CS, Yeung JH, Vandermeer B, Homik J. Bisphosphonates for steroid-induced osteoporosis. Cochrane Database Syst Rev. 2016;10:CD001347.

130. Kan SL, Yuan ZF, Li Y, et al. Alendronate prevents glucocorticoid-induced osteoporosis in patients with rheumatic diseases: A meta-analysis. Medicine (Baltimore). 2016;95(25):e3990. 
131. Rudic JS, Poropat G, Krstic MN, Bjelakovic G, Gluud C. Hormone replacement for osteoporosis in women with primary biliary cirrhosis. Cochrane Database Syst Rev.

2011(12):CD009146.

132. Dubreuil M, Ruiz-Gaspa S, Guanabens N, et al. Ursodeoxycholic acid increases differentiation and mineralization and neutralizes the damaging effects of bilirubin on osteoblastic cells. Liver Int. 2013;33(7):1029-1038.

41 